\title{
Body Ego and Trauma as Correlates of Comfort in the Physical Proximity of Others
}

\begin{abstract}
The purpose of the study was to investigate the associations between comfort in the physical proximity of others and interpersonal trauma and body ego. Comfort in the physical proximity of others was measured using a self-report method, as well as by means of a procedure where the experimenter initiated interpersonal touch. The results show that comfort in the physical proximity of others (based on self-report) was associated with four types of trauma (emotional, physical or sexual abuse and emotional neglect) as well as with all aspects of dysfunctional body ego (e.g. disrupted perception, problems with interpreting and regulating physical states). Defying expectations, the types of trauma studied did not differentiate individuals experiencing comfort from those experiencing discomfort, in an experimental setting of being touched. As predicted, both groups differed in all aspects of body ego. Moreover body ego proved to be a mediator between trauma and comfort in the physical proximity of others (self-report measure).
\end{abstract}

Key words: interpersonal touch, personal space, trauma, body ego, body image

Although the boundaries of our body determine the physical barrier between our self and our surroundings, it is accepted that there is a space around our bodies that when intruded upon by another person causes feelings of discomfort and anxiety. This space extends $70 \mathrm{~cm}$ from the surface of our skin (Hall, 1990; Hayduk, 1981). It is important to remember, however, that the extent of this space - coined by Hall (1990) as personal space - is quite varied. Firstly, there exist large cultural and individual differences regarding preferred distances. Secondly, even in the case of a single individual this space is subject to fluctuations at various times and in different situations (Hall, 1990; for review: Hayduk, 1983).

One of the hypotheses on the regulatory significance of personal space attributes the function of protection against dangers threatening one's physical and emotional well-being (Dosey \& Meisels, 1969; Hall, 1990). In this light, not only the objective danger to the self from another person is underscored, but the subjective factors that influence the way we interpret interpersonal relationships are also considered. Among these factors we find emotional state, as well as stable personality predispositions (including the image of one's own body). Results showed that schizophrenic (Deus \& Jokić-Begić, 2006) and borderline patients (Sakson, 2002), introverts (Williams, 1971), those with weakly developed body boundaries (Frede, Gautney, \& Baxter, 1968), aggressive (Cavallin \& Houston, 1980), those with a tendency to feel anxious (Patterson, 1977), and those in a state of anxiety (Ugwuegbu \& Anusiem, 1982) or stress (Dosey \& Meisels, 1969) prefer a greater interpersonal distance.

The aforementioned assumptions let us predict, that comfort in the physical proximity remains under the influence of the personality aspect - e.g. body image, which gives a shape to body experience and - as a consequence - to well-being. Body experience confusion can lead to defensive increasing both: interpersonal distance and discomfort in the physical proximity of other people. Contrary to other studies, where only the concept of constancy of the boundaries of one's own body has been conceptualized (e.g. Cavallin \& Houston, 1980; Sanders, 1976; Schlachter, 1971), this paper refers to the body ego model (Sakson-

* Institute of Psychology, Adam Mickiewicz University, Poznań, Poland 
Obada, 2009; Mirucka \& Sakson-Obada, 2013).

Moreover, although exploration of literature reveals many problems with regulating relations experienced by interpersonal-trauma victims (Herman, 2003; Terr, 1991; van der Kolk; 1996), very little is known about trauma impact on comfort in physical contact. Only a few clinical reports have striven to identify the problems in regulating interpersonal distance by trauma victims (Rothschild, 2000; Geanellos, 2003). To the best of my knowledge, only two studies have explored this problem in the field of sexual trauma (Skrzypska \& Suchanska, 2011) and physical abuse (Vranic, 2003). As we see presented in the literature below, the consequences of interpersonal trauma, give ground for hypothesis about discomfort in the physical proximity of others (Herman, 2003; Terr, 1991; van der Kolk, 1996). Thus, in the presented paper my interest focused on the following questions: (1) are personality aspect (body ego) and situational aspect (trauma) related to comfort in proximity of others, (2) does body ego as personality aspect, modify the relation between trauma and comfort in proximity of others?

It is worth mentioning that the theoretical model was based on the positively verified assumption, that trauma is a strong risk-factor for distorted body ego, and body ego shapes comfort in the physical proximity of others (Sakson-Obada, 2009). But it seems interesting to explore whether or not situational (trauma) and personal (body ego) aspects have similar viability to predicting discomfort in the physical proximity of others.

\section{Regulatory function of body ego in the context of comfort in the physical proximity of others}

In the field of psychology we can distinguish two ways of approach to body-mind phenomena. The first is represented by authors who study body aspects in a fragmentary way, without considering its influence on personality. Such categories as: body image (Cash, Pruzinsky, 2004; Derenne \& Beresin, 2006) attitudes toward the body (Brytek-Matera, 2011; Smolak, 2004; PokrajacBulian \& Zivcic-Bicirevic, 2005) sensations' awereness (Dunn, et al, 2007; Prinz, 2004) are singular aspect of body phenomena, mostly aplied to psychopathology explanation. The second approach is represented by authors who consider the possibility to experience ones body as the fundamental dimension for human personality. In these theories, the body is the "anchor of human identity" (Allport, 1998), "the place mediating all experience" (Krueger, 2002) and the "natural point of reference for everything, which happens inside and outside of the organism" (Damasio, 2002, pp. 264). The last mentioned idea is creatively developed in embodied cognition thesis in the field of cognitive science. Authors representing this idea, especially Bersalou, et al, (2003); Clark, (1996) and Lakoff and Johnson (1999), hold that all aspects of cognition are grounded in concrete, sensual experience. Cartesian dualism is therefore put into question, because even abstract representations are shaped by our body.

Thus, analysis of aforementioned literature (elaborated in works of Kowalik, 2003; Krueger, 2002; Mirucka 2003; Mirucka \& Sakson-Obada, 2013) suggest that experiencing one's body is crucial for sense of identity. Describing the link between ways of experiencing one's own body and comfort in the physical proximity of others, I will refer to the construct of body ego (Sakson-Obada, 2009; Mirucka \& Sakson-Obada, 2013). This concept was elaborated in order to present a cohesive conceptualization of body - mind phenomena. It was focused on the way one experiences his or her body but also include affective disposition toward body image.

Body ego is understood here as a part of ego structure, a part that organizes bodily experiences in the form of representations. Thus, body ego is a subsystem of ego since, unlike psychological ego, it is responsible for processing bodily experience on a mental plane.

The organization of bodily experiences is made possible by the functions of body ego. They are acquired and elaborated throughout the process of development, with significant participation of the persons taking care of the child (Sakson-Obada, 2008). The primary function of body ego is to perceive the stimuli coming from the interior of the body (e.g. muscle tone or heart beat) as well as those coming from the outside (e.g. tactile, olfactory or gustatory stimuli). In the case of strong body ego, the sensations are adequate, both: with respect to the modality and to the intensity of activation of the receptors. Further functions of body ego include interpretation of sensations, leading to such forms as emotions and physical states (e.g. hunger, fatigue or sexual arousal). Regulation of emotion and physical states is the last function of body ego. It is understood as knowledge of the causes and ways of coping with emotions and physical states. Putting it in other words, strong body ego enables the person to feel the changes taking place in their body (the function of perceiving), make the changes meaningful (the function of interpretation), and specify their causes and ways of coping with them (the function of regulating).

It was also assumed that the ability to feel, understand and cope with one's own bodily experiences should be reflected in in the emotional attitude to one's own body, as well as in the sense of one's physical identity. Putting it in other words, the ability of perceiving, correctly interpreting physical and emotional states and regulating them, is the basis on which one builds positive emotions toward one's body and such aspects of the sense of one's physical identity as: the core sense of existing (e.g. James, 1892/2002; Allport, 1998; Damasio, 2002), the sense of having physical boundaries (Moloney, 1957), as well as the sense of unity with one's own body (Krueger, 2002; Kowalik, 2003; Cole \& Paillard, 1995), the sense of its permanence in time and space (Jaśko, 1982). Many authors assume that the normal relationship between body and mind entails ,the state of quiet cooperation”, where the bodily functioning does not preoccupy excessively the attention of an individual (Erikson 1956; Torras de Bea 1987). In this respect, the sense of one's own bodily identity most frequently remains a ,silent" experience. This is due to the body ego's ability to integrate the sensations. The relation between functions, sense of one's physical identity and 
emotional attitude to one's own body was presented in the model below.

Figure 1. Model of body ego

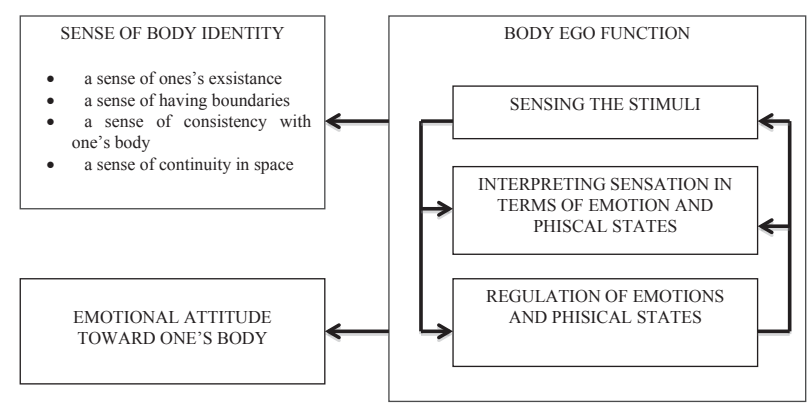

According to Erikson (1956), committing to a relationship with another person and building a relationship based on intimacy is not possible unless an individual has a stable point of reference in the form of adequate sense of identity. "True commitment - as writes Erikson (p. 78) in relations with others is both the result and a test of the stability of ones self image". One may thus suppose that establishing satisfactory physical and emotional contacts with others, is facilitated by proper orientation in one's own bodily experience. Such orientation allows selecting behavior that can be optimal for maintaining (or regaining) a state of well-being. Therefore, it seems very likely that individuals with strong body ego will find emotional and physical contacts with other people comfortable. Having an orientation in bodily experience and stable point of reference (sense of physical identity) enables them to regulate the physical distance so as to feel safe and comfortable. On the other hand, being lost in the world of one's own sensations, emotions and physical states may lead to difficulties in functioning in relationships with others. Then, the relationship is then prone to be perceived as the cause of disorientation and threat (Sokolik, 1993; Erikson, 1956; Zimberoff \& Hartman, 2002).

\section{Trauma and comfort in the physical proximity of others}

The manner of response to the close physical proximity of another person depends both on a sense of trust in others, as well as on the way one experiences oneself (e.g. Cavallin \& Houston, 1980). Experiences of trauma, particularly when the suffering is caused by another person, lead to changes in both of these perspectives, as they undermine the basic sense of selfhood, as well as fundamental human relations (Herman, 2003). These two aspects, namely distorted sense of identity and problems with initiating and maintaining relations are even considered as "core" symptoms of post-traumatic disorders, especially when trauma has interpersonal character, early onset and is long-lasting (see: avoidance cluster in PTSD and DESNOS - Disorders of Extreme Stress not Otherwise
Specified - Briere \& Scott, 2010; Herman, 2003; Perlman \& Courtois, 2005, and Posttraumatic Relationship Syndrome - Vandervoort \& Rokach, 2003).

Many authors emphasize, that interpersonal trauma - particularly when it involves violence that touches upon such important issues as intimacy, trust and trespassing on one's own physical boundaries - simultaneously violates a core sense of security (e.g. injured self - Herman, op. cit.) (Yule, Perrin \& Smith, 1999; Janoff-Bulman, 1992). Moreover, the experiencing of a traumatic event involves a confrontation with one's own terror and sense of helplessness, entailing the experience of being internally devastated person (van der Kolk \& Fisler, 1994), who is losing their sense of internal coherence and control over own life (Pynoos, 1995), as well as feeling shame, humiliation and guilt (Yule et al, 1999; Pynoos, Steinberg \& Goenjian, 1996). When suffering is caused by another human being not only self representation comes into question, but also the representation of others become distorted. Even single interpersonal trauma (e.g. sexual violence) can change the current direction towards relations with others. They are perceived as incapable of providing protection (Terr, 1995), or even as a potential source of threat (Janoff-Bulman, 1992).

The aforementioned consequences are much more persistent when interpersonal trauma is long lasting and, especially, when it takes place in childhood (Briere, Scott, 2010). According to many authors, abused and neglected children have well grounded negative representation of self and other people. Other people are experienced as source of threat, neglecting or indifferent to problems of trauma victims (Perlman \& Courtois, 2005; van der Kolk, 1996; Herman, 2003). For example experimental studies shown that abused children perceive angry facial expression faster than children who had not been maltreated (Pine et al, 2005).

Such consequences of trauma in the form of negative self and others representation incite one to assume, that this type of experience is a vital risk factor of discomfort in the physical proximity of other people. A few studies have shown that sexual interpersonal trauma is related with decreased engagement in couple relationship (Compton, 1999), revictimization and victimization of others (Luxenburg, et al, 2001). Moreover studies and clinical observations indicated that survivors of Holocaust suffer from feeling of loneliness and isolation (Prot a al, 2010) and fear of psychological closeness as well as rejection by other people (Prot, 2009). But to the best knowledge of the author of this paper, only two studies directly examined the relationship between trauma and comfort in physical closeness. Results obtained by Vranic (2003) revealed that personal space of physically abused children is larger than non-abused peers. Moreover Skrzypska and Suchanska, (2011), proved, that adult female victims of sexual trauma experience more discomfort in the physical proximity of others, than women without such experience. It seems interesting then, if other types of trauma can be considered as risk factor for discomfort in physical closeness.

Based on the above arguments, it was expected that 
interpersonal trauma and inadequate ways of experiencing one's own body would be associated with discomfort both in situations of close physical proximity of others (tested with self-report method), and in situations of interpersonal touch (initiated by the experimenter).

\section{METHOD}

\section{Subjects}

The subjects taking part in this research were selected during a screening of students attending three higher education colleges in Poznań, Poland. The purpose of this screening was to select a group that would participate in the main research on the basis of the results of self-report pertaining to the body ego (see the description of the method below). Because of the main goal of the research (verification of the body ego schema), the screening procedure had been planned so as to select 50 subjects with the highest results and 50 subjects with the lowest results in the questionnaire from a total of 200 participants. The leaflet attached to the questionnaire revealed the procedures which were going to be employed during individual meetings. In order to obtain 200 consenting participants for the next part of the study, it was necessary to examine 938 persons ( 393 males and 545 females). In the main research, 105 subjects (28 males and 77 females) aged 19 to 30 were engaged (mean age $=21.8$ years; $S D=2.61$ ). The methods used for verification of the hypotheses presented here will be described below.

An individual meeting with a researcher's assistant was the next part of the study. These took place in Institute of Psychology and last from 50 minutes to 90 minutes. Before starting, participants were reminded that: (1) one of the procedures relies on putting the hand of the researcher's assistant on the forearm of the participant and (2) questionnaire about traumatic events will be filled. After being reminded, participants were asked if they still want to take part in the study. Participants were also ensured that they could stop and quit the study at any moment. The order of method used at an individual meeting was as a result of the levels of intimacy and complexity. At the beginning, simple and non invasive self-report measure were used (Comfort in Close Physical Proximity Scale), then the procedure of interpersonal touch was applied. At the end participants completed a Traumatic Experiences Questionnaire. After the study an additional informative meeting was proposed, in which twelve participants took part.

\section{Instruments and procedures}

For the purpose of the study original methods were employed: Body Ego Questionnaire; Traumatic Experiences Questionnaire, Comfort in Close Physical Proximity Scale, the interpersonal touch procedure. ${ }^{1}$
Trauma exposure. The Traumatic Experiences Questionnaire is a 22-item self-report measure assessing the presence and severity of interpersonal traumatic events. It consisted five subscales, which responded to five types interpersonal trauma, e.g. (1) physical abuse (4 items, Cronbach's $\alpha=0,71$; e.g.: „I was beaten and I did not know what for"), (2) sexual abuse (4 items, Cronbach's $\alpha=0,61$; e.g. „I was forced into having sex against my will”), (3) emotional neglect (4 items, Cronbach's $\alpha=0,78$; e.g. „I felt they wouldn't care if I died"), (4) emotional abuse (5 items, Cronbach's $\alpha=0,73$; „When I wanted to cuddle up, I was pushed away or told to go away") and (5) physical neglect ( 5 items, Cronbach's $\alpha=0,37$; e.g.: „Nobody cared if I had anything to eat"). ${ }^{2}$ If participants admitted experiencing a traumatic event they were asked to evaluate: how many times they experienced the event, how old they were when the event occurred for the first time, the identity of the perpetrator(s), and the number of perpetrators. These circumstances, according to the literature, were likely to increase the possibility of developing a traumarelated disorder (Briere \& Scott, 2010; Cohen, Mannarino, Deblinger, 2011). Apart from summing up affirmative answer for occurrence traumatic situation (1- if situation took place, 0 - if not) the additional points were admitted if: (1) trauma took place before the age of six; (2) it happened more, than a few times in any given month; (3) the perpetrator was someone from the family of origin (4) the number of perpetrators was more than two (for more details see: Sakson-Obada, 2009). High scores reflected a higher presence and severity of a particular type of trauma.

Body Ego construct. The Body Ego Questionnaire is an instrument that serves to assess the severity of disturbances in body ego function (perceiving, interpretation and regulation), sense of physical identity and emotional attitude to one's own body. This self-report measure comprised of 67 statements and was developed by the author of the study (Sakson-Obada, 2009). Responses are made on Lykert type scale ranging from $1=$ not at all true to $5=$ extremely true. Higher scores reflected more disturbances in body ego. The basic function of body ego, which is perceiving of sensation was measured by two subscales. Both of them indicated disturbances in sensing of stimulus, but in opposite direction. First, a 10-item subscale (Cronbach's $\alpha=.74$,) included symptoms of elevated threshold for sensation e.g.: "Sometimes my whole body or a part of it is insensitive to pain". The second one included 7 items (Cronbach's $\alpha=.75$,) concerning lowered threshold for sensation and included such statements as: "Sometimes even a delicate touch is felt like something painful to me". Interpretation of bodily states, the second function of body ego, was measured using two subscales. Items represented one's ability to recognize bodily experience in term of emotions or physical states. The first subscale: Interpretation of emotions (Cronbach's $\alpha=.82$ ) included such statements as "I experience feelings

\footnotetext{
${ }^{1}$ Detailed information about the construction of the tools, the computation method and interpretation are available from the author.

${ }^{2}$ The low reliability of the subscale suggests that the experiences belonging to the category of physical neglect do not have to necessarily co-occur. Although the experiences do not have the features of a syndrome, it was decided to include the results of this scale in the computation.
} 
that I cannot identify at all". The second scale: Interpretation of physical states (Cronbach's $\alpha=.60$ ), may be represented by the statement: „I can go for several nights without sleep and not feel tired at all". The last function of body ego, e.g. regulation of bodily experience was measured by two subscales, which describe difficulty in both: recognizing the cause and coping with emotions (first subscale) and physical states (second subscale). The 9-item emotional regulation subscale ( $\alpha$ Cronbacha $=.78$, ) can be represented by the statement ,When I am joyful or happy, I know how to maintain this pleasant state". The 11-item regulation of physical states subscale (Cronbach's $\alpha=.74$,) includes, for example, the statement: „When I am sexually aroused, I know exactly, what has caused this state in me".

The sense of one's own physical identity was assessed using a scale, which consisted of 9 items (Cronbach's $\alpha=.84$ ). Items represented disturbances within aforementioned physical identity aspects (see Figure 1), for example "doubts concerning the boundaries of my body" or "experience that part of my body looks strange to me".

Emotional attitude to one's own body was measured using a 9-item scale (Cronbach's $\alpha=.90)$ and examined affective appraisal of body image. It included such statements as: „I like my looks, though I know it is not perfect" or "The way I look makes me ashamed".

The reliability of the entire questionnaire was estimated by means of calculating Cronbach's $\alpha$ is .95; while the distribution of results in the population of students participating in screening $(N=938)$ turned out to be normal (Kolmogorov-Smirnov test result $=0,975 ; p$ (two-sided $)=$ $.298 ; M=2.36 ; S D=.55)$.

Comfort in the physical proximity of others. This aspect was measured using a self-report method, as well as by means of a procedure where the experimenter initiated interpersonal touch. The Comfort in Close Physical Proximity Scale, developed by the author of the study, is a self-report measure. It serves to estimate the level of security and comfort in situations of close physical proximity of other people, including interpersonal touch.. It is comprised of 13 statements (e.g. ,I like physical contact with other people" or "I feel anxious while being touched by someone"), and its reliability, estimated by means of calculating Cronbach's $\alpha$, is .82. Responses were made on Lykert type scale ranging from $1=$ not at all true to $5=$ extremely true. Higher scores represented higher level of discomfort in physical contact with others.

Interpersonal touch procedure serves to assess comfort in situations of interpersonal touch initiated by the experimenter (a woman), and constitutes one of the parts of the procedure conducted during individual meetings. Before putting a hand on the forearm of the subject, the experimenter presented the following instruction: Now I am going to put my hand on your forearm and we will stay this way for a while (the experimenter placed her hand on the subject's forearm for 8 seconds). After the touch ceased, the subject was asked: whether the state was unpleasant, pleasant or neutral. Those categorized as feeling comfortable in situations of touch were persons who described their state during the procedure as pleasant or neutral while individuals who described their state as unpleasant were classified as feeling uncomfortable in the situation of touch.

\section{RESULTS}

Before setting out to verify the hypotheses, a check was made as to whether feelings that appeared during the experiment were coherent with what a person thinks of his or her responses to close proximity of other people. In order to do this, a comparison of the individuals reporting discomfort $(n=26)$ and those reporting comfort $(n=79)$ in the situation of interpersonal touch was conducted (T-test was used) in terms of the results obtained in the scale measuring comfort in close physical proximity of other people. It turned out that individuals who reported feeling unpleasant when touched by the experimenter declared (in the questionnaire) that they also tended to feel more uncomfortable when in close physical proximity of another person, compared to those for whom such a touch was comfort ( $M$ (touch discomfort) $=2.37, S D=0.66, M$ (touch comfort $)=2.93, S D=0.92$, $t(103)=-2.87, p<.001)$. The result allows one to draw the inference that there exists a relationship between the beliefs regarding emotional responses to close physical proximity of another person and the feelings an individual expresses during the interpersonal touch experimental procedure.

Using the test $\mathrm{Chi}^{2}$, the difference in evaluation of interpersonal touch between genders was checked. Difference appeared to be non significant $\left(\mathrm{Chi}^{2}(1)=\right.$ $3.08, p=.079)$. Therefore in further calculations, gender differences weren't taken account.

\section{Trauma and comfort while in close physical proximity of others}

In order to verify the hypothesis of the link between traumatic experiences and feelings evoked by close physical proximity of other people, correlation analysis was used when the first of the variables was measured by means of a self-report method, while the Student's t-test for independent samples was used when comfort in situations involving interpersonal touch was measured. The results of the correlation analysis allows one to conclude that discomfort in the situation of close physical proximity of other people is most strongly linked with emotional abuse $(r=.36, p<.001)$ and emotional neglect $(r=.36, p<.001)$, with the link being slightly weaker in case of sexual abuse $(r=.25, p<.01)$ and physical violence $(r=.24, p=0,01)$. At the same time, there was no link found between comfort in situations of close physical proximity of another person and experience of physical neglect $(r=.15 ; p>.05)$. The obtained results show that the emotional climate between caregiver and child is particularly important in determining the way one responds to close physical proximity of other people, however no less significant is the experience of attack on one's own body, involved in sexual abuse and physical violence. It is also worthwhile noting that all circumstances of trauma, which were recognized as factors that increased the likelihood of developing disorders, 
contributed to discomfort in situations of close physical proximity of other people in a significant way. This variable most strongly correlated with who the perpetrator of the traumatic event was $(r=.39, p<.001)$, as well as with the age of the victim of the trauma $(r=.37, p<.001)$; a slightly weaker link was found in case of frequency $(r=.27, p<$ .01 ); while the weakest link was found in case of the number of the persons involved $(r=.19, p<.05)$.

The intention was also to answer the question of whether comfort in situations of interpersonal touch is in any way linked to particular experiences of trauma. Comparisons of the intensity of particular types of trauma in groups of people who reported experiencing pleasure (or who declared the situation was neutral for them) with the results obtained by people who admitted to experiencing discomfort while touched by the experimenter did not exhibit any important differences. The results suggest that the appraisal of one's own state with respect to the dimension of "pleasant-unpleasant" in situations of being touched by the experimenter is not related to any traumatic experience in the studied group.

\section{Body ego and comfort in situations of close physical proximity of others}

In order to examine the relationships among particular aspects of declarative body ego, and comfort in situations of close physical proximity of other people, the correlation method was used. This established that all aspects of body ego were associated with comfort in situations of close physical proximity of other people. Therefore, the absence of a sense of security while in close physical proximity of another person was associated with: experiencing both states of excessive sensitivity $(r=.52$, $p<.001)$ as well as with reduced sensitivity to external stimuli $(r=.57, p<.001)$, problems with interpreting emotions $(r=.60, p<.001)$ and physical states $(r=.49, p$ $<.001)$, impaired emotional regulation $(r=.56, p<.001)$ and physical states $(r=.49, p<.001)$, negative emotions towards one's own body $(r=.38, p<.001)$. $)$, and also with disintegrated sense of physical identity $(r=.52, p<.001)$

Following this, examinations were made as to whether particular aspects of body ego differentiated the individuals in whom the touch initiated by the experimenter evoked negative feelings, and those in whom it evoked positive (or neutral) feelings. Inter-group comparisons with respect to particular aspects of body ego (by means of Student's test) are presented in Table 1.

The results obtained suggest that the groups differed significantly in all aspects of declarative body ego. The persons who assessed the situation of being touched as pleasant or neutral were less disturbed with respect to elevated or lowered threshold of sensations, emotion interpretation, interpretation of physical states, regulation of emotional and physical states, as well as a sense of identity. Moreover their emotions towards their own body were more positive than in the case of those who described their state during the experiment as negative. Thus, the results confirm the expectations regarding the regulatory function of body ego with respect to comfort in situations of close physical proximity of others which is reflected both in the beliefs a person holds regarding feelings experienced while finding themselves in the proximity of another person, as well as in particular emotional responses to touch initiated by the experimenter. Finally, a decision was made to answer the question of viability of predicting discomfort while in close physical proximity of other people, based on the studied aspects of body ego and trauma. For this purpose, the statistical model of linear multiple regression by the step method was used. The conducted analysis proved that the two aspects of declarative body ego are the best predictors of discomfort in the situation of close physical proximity of other people. These were problems with interpretation of emotions $(\beta=.45, t=5.05, p<.001)$ and elevated threshold of sensations $(\beta=.23, t=2.33, p<.02)$. They explain 44 percent of variance of the variable 'comfort in close physical proximity of others' $\left(R^{2}=.44, F(2,102)=40.66, p<0,001\right)$. Introducing the remaining variables did not result in any significant increase in the variation under scrutiny.

Table 1. Mean values of aspects of body ego in groups classified with respect to comfort and discomfort in the procedure of interpersonal touch

\begin{tabular}{|c|c|c|c|c|c|}
\hline \multirow{2}{*}{ Body ego } & \multicolumn{2}{|c|}{ comfort $(n=79)$} & \multicolumn{2}{|c|}{ discomfort $(n=26)$} & \multirow{2}{*}{$t$} \\
\hline & $M$ & $S D$ & $M$ & $S D$ & \\
\hline Elevated threshold & 1.90 & .69 & 2.25 & .77 & $-2.19^{*}$ \\
\hline Lowered threshold & 2.10 & .72 & 2.52 & .64 & $-2.65^{\star *}$ \\
\hline Emotion interpretation & 2.63 & 1.10 & 3.30 & 1.11 & $-2.69^{\star *}$ \\
\hline Physical state interpretation & 2.42 & .77 & 2.80 & .85 & $-2.09^{*}$ \\
\hline Emotion regulation & 2.90 & 1.01 & 3.46 & 1.06 & $-2.41^{\star *}$ \\
\hline Physical state regulation & 2.56 & .86 & 2.98 & .80 & $-2.20^{*}$ \\
\hline Emotions towards body & 2.60 & 1.15 & 3.13 & 1.17 & $-2.05^{\star}$ \\
\hline Sense of physical identity & 2.15 & 1.04 & 2.63 & 1.04 & $-2.06^{*}$ \\
\hline
\end{tabular}


Body ego as mediator between trauma and comfort in the physical proximity of others.

To verify the hypothesis about mediating effect of body ego between trauma and comfort in the physical proximity of others, the Sobel test was used. Only data from the proximity scale was taken to analysis because the interpersonal touch procedure wasn't associated with any type of trauma (yet, the first criterion to use Sobel test was not met). Besides, more general variables were included to analysis. It was: body ego strength (sum of all results obtained in the Body Ego Questionnaire) and trauma total score (sum of all results obtained in the Traumatic Experiences Questionnaire, except for physical neglect scale - analysis has not shown correlation with dependent variable).

The criterion, which should be met for body ego to mediate the association between trauma and comfort in the physical proximity of other states is, that all variables should be associated with each other. Table 2 shows the results of the analysis.

Table 2. Body ego as a mediator between trauma and comfort in physical proximity.

\begin{tabular}{|c|c|c|c|c|c|c|}
\hline Variables & Path & $B \pm S E$ & $B$ & $R 2$ & $t$ & $p$ \\
\hline $\begin{array}{l}\text { Trauma- } \\
\text { Body ego }\end{array}$ & A & $\begin{array}{l}.633 \\
(.113)\end{array}$ & .483 & .225 & 5.592 & $<.001$ \\
\hline $\begin{array}{l}\text { Body } \\
\text { ego-comfort }\end{array}$ & B & $\begin{array}{l}.128 \\
(.015)\end{array}$ & .631 & .393 & 8.259 & $<.001$ \\
\hline $\begin{array}{l}\text { Trauma- } \\
\text { Comfort }\end{array}$ & $\mathrm{C}$ & $\begin{array}{l}.097 \\
(.024)\end{array}$ & .364 & .124 & 3.971 & $<.001$ \\
\hline $\begin{array}{l}\text { Trauma- } \\
\text { Comfort }\end{array}$ & $C^{\prime}$ & $\begin{array}{c}.021 \\
(.023)\end{array}$ & .078 & .391 & .892 & .375 \\
\hline
\end{tabular}

Note. Sobel test: $z=4.298, p<.001$.

The results obtained indicate the mediating effect of body ego between trauma and comfort in the physical proximity of others $(z=4.298, p<.001)$.

\section{CONCLUSIONS AND DISCUSSION}

The purpose of the study was to research the associations between trauma and body ego on the one hand, and comfort while in close physical proximity of others on the other. The expected relations were stronger in situations where the dependent variable was presented in terms of one's opinions than when the way of reacting to close physical proximity of the experimenter in experimental setting was analyzed. One of the possible explanations of such results is the way of measuring the manifestations of physical comfort as well as of the remaining variables. Self-report methods used for measuring the variable, as well of trauma and body ego, refer to overt and general knowledge that does not take into account experiences different from these beliefs. Verification of the presumed interdependencies by means of such methods allows one to obtain a more coherent picture, compared to that which emerges when we study particular behavior in a specific experimental setting (i.e. procedure of interpersonal touch; Mischel, 2004).

The results of the study showed that abnormalities in the functioning of body ego allow one to predict discomfort in situations of close proximity of other people as recorded in the form of opinions more than different types of trauma. Moreover only disturbances within all functions of body ego and negative emotions toward one's own body were related to the admission of experiencing discomfort in situations of interpersonal touch. These results lead to the conclusion that a disturbed way of experiencing one's own body is a greater risk to the sense of security in physical contacts than the fact of experiencing trauma. This result seems to be significant since in previous research dealing with the problem of determinants of personal space, variables related to body ego were either overlooked, or understood in a very limited manner (e.g. as the level of distinctiveness of the boundaries of a person's own body - Cavallin \& Houston, 1980; Sanders, 1976; Schlachter, 1971).

It is also worth turning one's attention to the aspects of body ego that were the strongest predictors of discomfort while in close physical proximity to other people. It is worth remembering that 44 percent of variance in the variable was explained by the interaction of an elevated level of sensations and problems with interpreting emotions. It seems that elevating the thresholds of sensations may fulfill the function of defense mechanisms that allows a person to dissociate themselves from sensations related to close physical proximity of other people, when it is interpreted as invasive. On the other hand, the state of absence (or reduction) in sensitivity to sensory stimuli may hinder the orientation towards the partner of the interaction, which may in turn lead to experiencing close physical proximity of others as unpleasant and lead to avoidance of contact. Similar problems with identifying one's own emotions, fulfilling the signaling function in regulating behavior may lead to difficulties in establishing such distance in relationships with other people where the person feels safe or comfortable.

Lastly, the relationship between trauma and discomfort in situations of close physical proximity of other people needs to be discussed. As it was expected the results lead to the conclusion that early experience of interpersonal trauma, where the perpetrator is the caregiver of the child, has a negative effect on the way one responds to the close physical proximity of other people (measured by means of self-report method). And so it turned out that experience of physical, emotional and sexual abuse, as well as emotional neglect, was associated with distress in situations entailing close physical proximity of other people, and the resulting avoidance of such situations. The obtained results confirm the hypothesis on the generalized attitude of distrust of others resulting from recurring painful experiences involved in relationships with the closest ones (Herman, 1995). However it should be emphasized that conducted analysis revealed no direct influence trauma on physical closeness. As we remember body ego is mediator between these two aspects. One possible explanation is, that only when trauma 
leaves its mark in the body ego we can expect discomfort in physical contact with others. Another explanation is, that a disordered body ego increases the influence of trauma on comfort in physical contact with other people so can be consider as protective or amplifying effects of trauma factor.

It also should be remembered that none of the types of trauma, were related to assessment of interpersonal touch on the dimension of pleasure, which in light of the above presented results is rather surprising. Such a finding may be interpreted in at least two ways. The first explanation refers to difficulties with establishing optimal personal distance by victims of trauma. Clinical observations conducted by Rothschild, (2000), and Geanellos, (2003), show that individuals asked to describe the distance in which they feel secure and comfortable in relation with another person estimate it either as inadequately long, or they are not able to indicate the moment, when the close proximity of another person begins to be sensed as unpleasant. Therefore, it is not impossible that the attitude to interpersonal touch may be of two types, namely it may be neutral or decisively negative. If the above argument is correct, it would mean that similar number of trauma victims are found in the group experiencing comfort as in the group of subjects declaring discomfort in the situation of touch. A question should be posed, however, whether the postulated indifference towards touch in trauma victim is identical with the neutral attitude towards touch initiated by the experimenter in so called "healthy" individuals. It cannot be ruled out that indifference in trauma victims is a state that may be registered on the conscious level, and one that may be different from the actual aroused emotion (e.g. anxiety). In other words, it can be assumed that in a number of trauma victims (declaring indifference) defense mechanisms were at work which disabled the awareness of negative emotions. Although such hypothesis would require verification through research planned differently (e.g. registering nonverbal manifestations of emotions in the procedure of interpersonal touch), some confirmation of it can be found in the results of the present study, showing that experience of interpersonal trauma was accompanied by both exaggeration of the intensity of one's arousal, as well with registering many numerous changes in one's own body in the described experimental setting. Finally, the most obvious explanation for the above, namely that experiencing trauma does not affect emotional attitude towards touch in general or touch that is fairly „,neutral” (i.e. not involved in any intimate relationship), cannot be ruled out either.

Summarizing the obtained results, it may be concluded that the way of experiencing one's own body is crucial for regulating of interpersonal space. Moreover painful relationship experiences are vital factors affecting the comfort physical closeness, however their influence is mediated by body ego. It means that harmful effects of interpersonal trauma can be reduced by enhancement of body ego. Providing positive experience of the body (e.g. massage and other pleasant stimulation) can be recommended for trauma victims.

Moreover, the results of the conducted research confirm the hypothesis that extending personal space may serve the purpose of regulation (protection against negative feelings (Dosey \& Meisels, 1969; Uzzell \& Horne, 2006) evoked both by a sense of being lost in the world of one's own bodily experiences, as well as by a generalized sense of insecurity in relationships with other people.

\section{References}

Allport, G. (1998). Osobowość i religia. [Personality and religion]. Warszawa: Instytut Wydawniczy Pax.

Bersalau, L. W., Niedenthal, M. P., Barbey, A. K., \& Ruppert, J. A. (2003). Social Embodiment. The psychology of learning and motivation, 43, 4386.

Briere J., \& Scott, C. (2010). Podstawy terapii traumy. Diagnoza i metody terapeutyczne. [Principles of trauma therapy: A guide to symptoms, evaluations and treatment]. Warszawa: Instytut psychologii zdrowia.

Brytek-Matera A. (2011). Body attitudes and self-representation in women with eating disorders. Research based on Edward Tory Higgins' selfdiscrepancy theory, Psychiatria Polska, 45(5), 671-682.

Cash T.F., \& Pruzinsky T. (2004). Body Image. A Handbook of Theory, Research, \& Clinical Practice. New York: The Guilford Press.

Cavallin, B. A. \& Houston, B. K. (1980). Agressiveness, maladjustment, body experience and the protective function of personal space. Journal of Clinical Psychology, 56, $170-177$.

Cohen, J., Mannario, A. P., \& Deblinger, E. (2011). Terapia traumy $i$ traumatycznej żałoby u dzieci i młodzieży. [Trating trauma and Traumatic Grief in Children and adolescents]. Kraków: Wydawnictwo UJ.

Cole, J., \& Paillard, J. (1995). Living without touch and peripheral information about body position and movement: Studies with deafferented subjects. In J. L. Bermudez, A. Marcel \& N. Eilan (Eds.). The Body and the self (pp. 245-266). Cambridge: A Breadford Book.

Compton, J. S. (1999) Using observational coding to examine intimacy process and affective expression. Dissertation Abstracts International: Section B: The Sciences and Engineering, 60 (1-B), 0361.

Damasio, A. (2002). Bład Kartezjusza. [Descartes' error]. Warszawa: Dom Wydawniczy Rebis.

Derenne, J.L., \& Beresin E.V. (2006). Body image, media, and eating disorders, Academic Psychiatry, 30, 257-261.

Deuš,V., \& Jokić-Begić, N. (2006). Personal space in schizophrenic patients. Psychiatria Danubina, 18(3-4), 150-158.

Dosey, M. A., \& Meisels, M. C. (1969). Personal space and self-protection. Journal of Personality and Social Psychology, 11, 93-97.

Dosey, M. A., \& Meisels, M. C. (1971). Personal space, anger - arousal and psychological defense. Journal of Personality, 39, 333-344.

Dunn, B., Dalgleish, T., Ogilvie, T. A., \& Lawrence, A. D. (2007) Heartbeat perception in depression, Behaviour Research and Therapy, 45, 1921-1930.

Erikson, E. (1956). The problem of ego identity. American Journal of Psychoanalytic Association, 4, 56-118.

Frede, M.C., Gautney, D. B., \& Baxter, J. C. (1968). Relationships between body image boundary and interactions patterns on the MAPS test. Journal of Consulting and Clinical Psychology, 32, 575-578.

Geanellos, R. (2003). Understending the need for personal space boundary restoration in women-client survivors of intrafamilial childchood sexual abuse. International Journal of Mental Health Nursing, 12, $186-194$.

Hall, E. (1990). The hidden dimension. New York: Anchor Books.

Hayduk, L. A. (1981). The permeability of personal space. Canadian Journal of Behavioural Science, 13, 274-287.

Hayduk, L. A. (1983). Personal space: Where we now stand. Psychological Bulletin, 94, 293- 335.

Herman, J. (2003). Uraz i powrót do równowagi. [Trauma and recovery]. Gdańsk: Gdańskie Wydawnictwo Psychologiczne.

Herman, J.L. (1995). Complex PTSD: A syndrome in survivors of prolonged and repeated trauma. G. Everly, J. Lating (Eds.), Psychotraumatology: Key papers and core concepts in post-traumatic stress (pp. 87-100). New York: Plenum Press.

James, W. (1892/2002). Psychologia. Kurs skrócony. [Psychology. Briefier Course]. Warszawa: Wydawnictwo Naukowe PWN.

Janoff-Bulman, R. (1992). Shattered assumptions: Towards a new 
100

Olga Sakson - Obada

psychology of trauma. New York: Free Press.

Jaśko, P. (1982). Deprywacja somatosensoryczna a wczesny rozwój. [Somatosensory deprivation and development]. Przeglad Psychologiczny, 25, 89-100.

Kowalik, S. (2003). Ja cielesne-próba nowego spojrzenia. [The physical self- an attempt at new approach]. Polskie Forum Psychologiczne, 1: $5-29$.

Krueger, D. (2002). Integrating body self and pychological self. New York, London: Brunner- Routledge.

Lakoff, G., \& Johnson, M. (1999). Philosophy In The Flesh: the Embodied Mind and its Challenge to Western Thought. New York: Basic Books.

Luxenberg, T., Spinazzola, J., \& van der Kolk, B. A. (2001). Complex Trauma and Disorders of Extreme Stress (DESNOS) Diagnosis, Part I: Assessment.Directions. Psychiatry, 21, 373-393. Long Island City, NY: The Hatherleigh Company, Ltd.

Mirucka, B. (2003). Ja cielesne fundamentem tożsamości. [Physical self as personality basis]. Polskie Forum Psychologiczne, 8, 30-40.

Mirucka, B. (2005). Typy ja cielesnego, czyli sposoby doświadczania swojej cielesności przez kobiety. [Types of body self, the women ways of experiencing own body]. Czasopismo Psychologiczne, 11 6-26.

Mirucka, B., \& Sakson-Obada, O. (2013). Ja cielesne. Od normy do zaburzeń. [Body self. From norm to pathology]. Gdańsk: Gdańskie Wydawnictwo Psychologiczne.

Mischel, W. (2004). Toward an integrative science of the person. Annual Review of Psychology, 55,1-22.

Patterson, M. L. (1977). Interpersonal Distance, affect, and equilibrium theory. The Journal of Social Psychology, 101, 205-214.

Pearlman, L. A., \& Courtois, C. A. (2005). Clinical applications of the attachment framework: Relational treatment of complex trauma. Journal of Traumatic Stress, 18, 449-459.

Pine, D. S., Mogg, K., Bradley, P., Montgomery, L. A., Monk, C., McClure, E., Guyer, A. E., Ernst, M., Charney, D. S., \& Kaufman,J. (2005). Attention Bias to Threat in Maltreated Children: Implications for Vulnerability to Stress-Related Psychopathology. American Journal of Psychiatry, 162, 291-296.

Pokrajac-Bulian, A. \& Zivcic-Becirevic, I. (2005). Locus of control and self-esteem as correlates of body dissatisfaction in croatian university students. European Eating Disorders Review. 13, 54-60.

Prinz, J. J. (2004). Gut reactions. Oxford: Oxford University Press

Prot, K. (2009). The study of distant effect of Holocaust trauma. Psychotherapy 4(151), 65-76.

Prot, K., Biedka, Ł., Szwajca, K., Bierzyński, K., Domagalska, K., \& Izdebski, R. (2010). Groups psychotherapy of Holocaust survivors authors' own experience. Psychotherapy, 1(152), 25-35.

Pynoos, R. S. (1995). Traumatic stress and developmnental psychopathology in children and adolescents. In R. Pynoos (Eds.) Posttraumatic stress disorder: A clinical review (s. 65-98). Baltimore, MD, US: The Sidran Press.

Rothschild, B. (2000). The body remembers. New York: W. W. Norton \& Company.

Sakson, O. (2002). Zwiazek poczucia własnego ciała z autodestrukcjq $u$ osób borderline. [The relationship between body sense and selfdestuction of the borderline persons]. Unpublished master thesis.

Sakson-Obada, O. (2008). Rozwój Ja cielesnego w kontekście wczesnej relacji z opiekunem. [Body ego development in context of early relationship with caregiver]. Roczniki Psychologiczne, 11(2), s. $27-$ 44.

Sakson - Obada, O. (2009). Pamięć ciała. Ja cielesne relacji przywiazania $i w$ traumie. [Memory of a body. Body ego in trauma and attachmen relationship].Warszawa: Difin.

Sanders, J. L. (1976). Relationship of personal space to body - image boundary definiteness. Journal of Research in Personality, 10, 478 481

Schlachter, L. C. (1971). The relation between anxiety, perceived body and personal space andactual body space among young female adults. Dissertation Abstracts International, 32, 3458

Skrzypska, N., \& Suchanska, A. (2011). Sexual trauma as a risk factor of disorders in experiencing of one's own body. Polish Sexuology, 9 (2), pp. 51-56

Smolak L,. (2004). Body image in children and adolescents: where do we go from here? Body Image, 1, 15-28;

Sokolik, M. (1993). Psychoanaliza i Ja. Kliniczna problematyka poczucia tożsamości. [Psychoanalysis and self. The clinic of sense of identity].
Warszawa: Jacek Santorski \& CO Agencja Wydawnicza

Terr, L. C. (1995). Childhood traumas: an outline and overview. In G. S Everly \& J. M. Lating (Eds.), Psychotraumatology. Key papers and core concepts in post - traumatic stress (pp. 301-320). New York: Plenum Press.

Terr, L.C. (1991). Childhood traumas: an outline and overview. American Journal of Psychiatry, 148, 10-20.

Ugwuegbu, D. C. \& Anuziem A. U. (1982). Effects of stress on interpersonal distance in a stimulated interview situation. Journal of Social Psychology, 117, 3-7,

Uzzell. D., \& Horne, N. (2006) The influence of biological sex, sexuality and gender role on interpersonal distance, British Journal of Social Psychology, 45, 579 - 597.

Van der Kolk, A.B. \& Fisler, R. (1994). Childhood abuse and neglect and loss of self- regulation. Bulletin of the Menninger Clinic, 58, 145-169.

Van der Kolk, B.A. (1996). The complexity of adaptation to trauma. In A.B. van der Kolk, \& A.McFarlane (Eds.), Traumatic stress (pp. 182213). New York: The Guliford Press.

Vandervoort, D. \& Rokach, A. (2003). Posttraumatic relationship syndrome: The conscious processing of the world of trauma. Social Behavior and Personality, 31, 675-686.

Vranic, A. (2003). Personal space in physically abused children. Environment and Behavior, 35(4), 550-565.

Williams, J. L. (1971). Personal space and its relation to extraversionintroversion. Canadian Journal of Behavioural Science/Revue canadienne des sciences du comportement, 3(2), 156-160.

Yule W., Perrin, S.\& Smith, P. (1999). Post - traumatic stress reaction in children and adolescents. In W. Yule (Eds.), Post- traumatic stress disorders: Concept and therapy (pp.25-50). London: John Wiley \& Sons Ltd.

Zimberoff, D., \& Hartman, D. (2002). Attachment, detachment, nonattachment: Achieving synthesis. Journal of Heart-Centered Therapies, 5 (1), 3-94. 